\title{
Linking Academic Integrity and Classroom Civility: Student Attitudes and Institutional Response
}

Troy Brooks, Zopito Marini, \& Jon Radue

Brock University

This paper explores the notion that student behaviour regarding academic integrity and classroom civility are linked, and that intervention methods used to resolve classroom incivility may be used as a response to academic dishonesty. We advance the view that academic integrity and classroom civility refer to a student's willingness to respect the rules and regulations of the institution; and that, acts of academic dishonesty and incivility refer to student behaviour in breach of institutional policy andlor not consistent with the social norms of the institutional culture (e.g., inappropriate human interactions). The perceptions and attitudes of first-year students toward academic integrity as they transition from high school to university are examined. Two hundred and thirty-nine first-year students volunteered to participate in this study. The preliminary findings of the open ended response regarding their observations and experiences with cheating and plagiarism in high school and in university are reported with a view to offer suggestions regarding institutional intervention strategies.

\section{Introduction}

$\mathrm{T}$ he general purpose of this paper is to broaden our understanding of the nature of student academic dishonesty and academic in/civility ${ }^{1}$ by investigating the potential usefulness of the idea that academic integrity can be conceptualized as part of the academic civility environment. The specific objectives of our study were: 1) to extend previous lit- erature by developing a questionnaire designed to assess students' beliefs and perceptions of academic integrity and in/civility; and 2) how this can be useful in the development of prevention programs that support student academic success.

In this paper we would like to advance the notion that issues of academic integrity (e.g., cheat-

\footnotetext{
${ }^{1}$ In this manuscript we use the term "in/civility" to convey the continuum between incivility and civility.
} 
ing and plagiarism) share common underlying roots with classroom incivility (e.g., behaviours that are not consistent with the social norms of the institution). That is to say, academic integrity can be considered part of the general umbrella of civility suggesting that acts of academic dishonesty are related and spring from the same cognitive and emotional source as classroom incivility.

More specifically, we highlight two unique commonalities based on the issues of similar continuum and motivation. For instance, acts of incivility can range from minor incidences, such as when classes and seminars are disrupted by loud conversations, to more serious ones, such as when discussions turn into verbal or physical confrontations. By comparison, acts of academic dishonesty can manifest themselves in many ways: from incorrect citation to inappropriate collaboration to more egregious occurrences involving the deliberate copying of test or exam answers where serious breaches of academic policy are undeniable.

In addition to similarities in the continuum between academic integrity and civility, it can be further argued that, much like behaviours of incivility, some instances of academic dishonesty can occur as a result of thoughtlessness and unintentional acts, while other academically dishonest behaviours can be premeditated and intentional.

In recent years there has been increased recognition in classroom in/civility as evidenced by the research from a number of perspectives (see Carter, 1998; Forni, 2005; Hirschy \& Braxton, 2004; Marini, 2009). This awareness has led to better understanding of this phenomenon and greater efforts in improving teaching and classroom environments.

The reality is that investigations into academic integrity and academic in/civility are becoming increasingly complex and there is a need to explore these phenomena from a broader perspective, which must include students' own beliefs and attitudes.

\section{Methodology}

Our instrument, the Academic Integrity \& Civility Questionnaire (Brooks, Marini \& Radue, 2009), was designed to assess student perceptions and attitudes towards academic integrity and classroom civility. It is a 73-item Likert scale questionnaire, with an additional item requiring an open-end response regarding cheating/plagiarism.

The questionnaire was administered to first-year students during their first-term of postsecondary education. This is often a critical time as students make their transition from high school to university. Students from two first-year university classes (one from the Faculty of Social Sciences, with an enrolment of 579; the other from the Faculty of Mathematics and Science, with an enrolment of 171) participated in the study. Of the 239 questionnaires completed, 179 came from students in the Social Sciences and 60 from students in Mathematics and Science; representing a response rate of $30.9 \%$ and $35.8 \%$ respectively.

A theoretical content analysis of the responses to the open ended statement was completed, and themes were extracted based on the frequency of similar responses (see Weber, 1990).

This present study, reports results from the open-ended response: "We would appreciate having your comments on cheating/plagiarism referring to your university and/or high school experience."

These themes serve to 1) identify what students know about academic integrity and in/ civility; 2) highlight the challenges that transitioning from high school to university present; and 3) capture the perceptions and attitudes students hold regarding academic integrity and in/civility.

\section{Results}

The analysis generated four themes, presented below, which reflect the perceptions and attitudes of students' related to their experience with cheating/ plagiarism. We include actual comments taken from the questionnaire to illustrate how students relate to the issue of academic integrity.

\section{Perceptions and attitudes (19.9\%)}

Student attitudes on academic integrity were mixed. Many students stated that academic dishonesty is 
disrespectful and unfair to those who act honestly. There was also a strong sense that cheaters and plagiarizers, particularly those who act intentionally, should be punished:

"I just think that it disrespects other people; for the work that they put into faking it is just an act of incivility."

"Plagiarism is a form of breaking the law, it's an illegal act that should be punished."

Some students were able to draw distinctions between intentional and unintentional plagiarism and advocate differential consequences. In other words, students feel that those who intentionally plagiarize should be punished while those who plagiarize unintentionally should not be punished, or not with the same severity:

"Those who plagiarise[sic] on purpose should be punished. However, unintentional plagiarism should have smaller consequences."

"It is not acceptable, but people who don't realize they are plagiarizing should not get into trouble."

\section{High school experience (17.9\%)}

Students are of the opinion that high schools should do a better job at preparing students for the expectations of university, particularly when it comes to issues of academic integrity:

"Cheating is wrong, but high school does not always teach students how to cite properly."

“... If teachers in high school began educating students from the get-go, students would be used to it and more familiar with by the time they reached university..."

\section{Transition: Hierarchy of understanding (17.4\%)}

The transition from high school to university seemed of high importance to students, and also appears to provoke a great deal of anxiety. Many students indicated that there is not a great deal of emphasis placed on academic integrity in high school in comparison to university; with some students stating that the increased emphasis has made them scared to make a mistake:

"I was not prepared for the seriousness of cheating/plagiarizing that is presented in university."

"Submitting assignments to Turnitin makes me extremely nervous, because I would never intentionally plagiarize...”

\section{Is the institution doing a good job of informing students (17.2\%)?}

Students indicated that they are being informed, but feel that a clear and consistent message should also be given on the importance of proper citation; and instructors and teaching assistants should be doing more to help educate them on proper citation.

"I noticed that the university makes students aware of cheating plagiarism more than anywhere else I've been.”

"I feel I have been well educated on what plagiarism is, what the consequences are \& where to go for extra help."

"Professors should post examples or instruct TA's to spend a seminar going over it."

The remaining responses identified related issues such as peer behaviour, the stress of balancing priorities and academic work load, which are consistent with concerns expressed by students at our own institution (see Christensen Hughes \& McCabe, 
2006b; McCabe \& Treviño, 1997).

"Sometimes the pressure of 5 courses combined with poor time management skills and the too many distractions we have as students plagiarizing, even just a little makes everything seem just a little easier."

"Personally if I'm crunched for time it seems better to plagiarize $\&$ hand it in rather than getting a zero esp.[sic] if you know that with more time you could complete it properly."

Other responses identified primarily that academic dishonesty was bad, but did not offer further elaboration.

"Plagiarism is wrong plus you'll usually get caught."

"Don't cheat."

These miscellaneous statements $(27.6 \%)$ will be further analyzed as the study progresses, and located into appropriate themes.

\section{Discussion}

The present findings indicate that students understand the importance of academic honesty; they comment that by comparison to their high school experience, there is more emphasis placed on academic integrity in university. However, students tended to focus on a mechanistic and much narrower behavioural interpretation, such as equating plagiarism solely as a failure to cite properly without taking into consideration the broader ethical and moral aspects of their academic (dis)honesty. In other words, students seem to put more importance on the 'technical' aspects of plagiarism rather than the psychological roots of the underlying behaviour.

In general, students agree that academic dishonesty is disrespectful and unfair to those who act honestly, but fail to see the serious and pervasive impact these behaviours have on the learning environment. Students who are witness to, or victim of classroom incivility may experience discomfort or animosity towards the perpetrator of the uncivil act. This may express itself by students not wanting to work with the offending student(s) on group assignments or in a seminar setting. Conversely, students who engage in academically dishonest behaviour who are found out by their peers may experience similar types of mistrust and derision from their peers.

The similarities between acts of academic dishonesty and acts of classroom incivility can become of great interest and potentially useful in planning interventions. For example, addressing the behaviour of two students exchanging answers during an inclass test could have a similar disruptive impact on the learning environment as addressing the behaviour of two students challenging a professor's marking scheme in an open classroom. Another parallel can be seen in situations where a students' behaviour becomes a serious breach of university policy, such as a physical altercation between students in a seminar, or the discovery of a group of students cheating on a test or exam.

The argument is that these academically dishonest behaviours are acts of incivility, because of the impact they have on the learning environment, which is often overlooked. These situations have an effect on others (instructors and students) who must re-engage with the learning process.

In some cases, acts of academic dishonesty can be very complex and occur in conjunction with behaviours considered to be uncivil, morally questionable and illegal (i.e., situations where a student might steal a test or exam and sell it to classmates). While these acts may occur in the isolation of a classroom, or other academic environment, their impact can be felt directly and indirectly across the university community (victims, witnesses, administrators, faculty members, teaching assistants, and peers), often requiring the institution to employ similar or reciprocal intervention approaches as a response to the behaviour.

Post-secondary institutions seem to be 
doing a good job at identifying academic integrity as an important issue. However, there seems to be inconsistency in how institutions respond to the various academically dishonest behaviours as well as the level of commitment demonstrated by instructors and teaching assistants (see Christensen Hughes \& McCabe, 2006a; McCabe \& Treviño, 1997). This suggests that the institutions have an important role in the socialization of student behaviour.

\section{Implications}

Academically dishonest behaviours are acts of 'academic incivility' and can be viewed belonging to a subtype of classroom incivility. Much like incivility, academically dishonest behaviour can be influenced by one's own personal philosophy, that is, how an individual personally feels about ethical behaviour. Other factors such as the attitudes and actions of one's peers or the response of the institution or persons in authority to a student's behaviour send a powerful message: identifying acceptable and unacceptable modes of conduct. Research supports the notion that individual and environmental factors, such as the desire to succeed, difficulty managing multiple priorities, and peer behaviour are related to student academic dishonest behaviour (see Ashworth, Bannister, \& Thorne, 1997; Christensen Hughes \& McCabe, 2006b; Crown \& Spiller, 1998; McCabe \& Treviño, 1997; Whitley and Keith-Spiegel, 2002).

This implies that methods of interventions for classroom incivility (see Lochman et al., 2009; Marini, Polihronis, \& Blackwell, 2010) may also be used to educate students as a means to prevent future academically dishonest behaviour. As an example Dee and Jacob (2010) suggest that intervention by way of increasing student knowledge regarding academic integrity rather than by increasing the perceived probabilities of detection and punishment can reduce the incidence of plagiarism.

Post-secondary institutions have been working hard in recent years on their response to academic (misconduct behaviours) and non- academic (incivility behaviours) discipline. This is evidenced by the increased use of restorative justice models, such as developing seminars for academic integrity and uncivil offenders that include a reflective assignment designed to create awareness of the impact of their actions while "holding the offender accountable for their actions in a more meaningful way than simply imposing further penalty" (Latimer \& Kleinknecht, 2000, p. 4), as a part of or as an option to discipline.

We may be able to draw from literature on interventions for classroom antisocial behaviour and incivility and consider ways that may used to reinterpret current strategies employed to promote academic integrity, educate students on academic honesty, and manage the administrative processes relating to the discipline of academic dishonesty. In particular, we suggest the following initiatives:

1. Provide appropriate and substantive consequences for academic dishonest behaviour, by making academic honesty and civility part of the curriculum and evaluation. For example, essay assignments could include a component requiring students to reflect and explain how the topics of integrity and civility have relevance to them.

2. Model academically honest behaviour and include regular discussions on ethical behaviour and acting with integrity throughout the term.

3. Provide a consistent institutional response to breaches of academic integrity policy.

4. Share the institutional meaning of academic integrity and civility and providing a consistent message across the university community.

5. Place the focus on prevention by providing and promoting programs designed to help students achieve academic success, such as timemanagement, essay writing labs, and student counseling. 


\section{References}

Ashworth, P., Bannister, P., \& Thorne, P. (1997). Guilty in whose eyes? University students' perceptions of cheating and plagiarism in academic work and assessment. Studies in Higher Education, 22(2), 187-203

Brooks, T., Marini, Z.A., \& Radue, J. (2009). Academic Integrity \& Civility Questionnaire (AICQ-Ver.1). Unpublished manuscript, Brock University.

Carter, S.L. (1998). Civility: Manners, morals, and the etiquette of democracy. New York, NY: HarperCollins.

Christensen Hughes, J.M. \& McCabe, D. (2006a). Academic misconduct within higher education in Canada. The Canadian Journal of Higher Education, 36(2), 1-21.

Christensen Hughes, J.M. \& McCabe, D. (2006b). Understanding academic misconduct. The Canadian Journal of Higher Education, 36(1), 49-63.

Crown, D.F. \& Spiller, M.S. (1998). Learning from the literature on collegiate cheating: A review of empirical research. Journal of Business Ethics, 17, 683-700.

Dee, T.S. \& Jacob, B.A. (2010). Rational ignorance in education: A field experiment in student plagiarism. Working Paper 15672. National Bureau of Economic Research.

Forni, P.M. (2005, November). The other side of civility. Johns Hopkins Magazine.

Hirschy, A.S. \& Braxton, J.M. (2004). Effects of student classroom incivilities on students. New Directions for Teaching and Learning, 99, 67-67.
Latimer, J. \& Kleinknecht, S. (2000). The effects of restorative justice programming: A review of the empirical. Research and Statistics Division. Department of Justice Canada.

Lochman, J., Boxmeyer, C., Powell, N., Qu, L., Wells, K., \& Windle, M. (2009). Dissemination of coping power program: The importance of intensity of counselor training. Journal of Consulting and Clinical Psychology, 77(3), 397-409.

Marini, Z.A. (2009). The thin line between civility and incivility: Fostering reflection and self-awareness to create a civil learning community. Collected Essays on Learning and Teaching, 2, 61-67.

Marini, Z.A., Polihronis, C., \& Blackwell, W. (2010). Academic in/civility: Co-constructing the foundation for a civil learning community. Collected Essays on Learning and Teaching, 3, 89-93.

McCabe, D.L. \& Treviño, L.K. (1997). Individual and contextual influences on academic dishonesty: A multicampus investigation. Research in Higher Education, 38, 379-396.

McCabe, D.L., Trevino, L.K., \& Butterfield (2002). Honor codes and other contextual influences on academic integrity. Research in Higher Education, 43(3), 357-378.

Weber, R.P. (1990) Basic content analysis (2nd ed.). Newbury Park, CA: Sage Publications.

Whitley, B.E. \& Keith-Spiegel, P. (2002). Academic dishonesty: An educator's guide. Mahwah, NJ: Lawrence Erlbaum Associates.

\section{Authors' Note}

The present paper is largelybased on material presented 
at the 2010 STLHE Conference in Toronto, and the CACUSS 2010 Conference in Edmonton, and is part of our on-going research program on academic integrity and in/civility.

\section{Biographies}

Troy Brooks is the Academic Integrity Officer at Brock University, and has worked in student judicial affairs for close to 15 years. His interests include academic integrity, moral development, reasoning, and disengagement as they relate to student behaviour.

Zopito Marini is a Professor of Child and Youth Studies at Brock University, his commitment to the scholarship of teaching and learning has been acknowledged with many awards from Brock University, the Ontario Confederation of Faculty Associations (the OCUFA Teaching Award, 2006), and the 3M National Teaching Fellowship (2010).

Jon Radue is an Associate Professor in the Department of Computer Science at Brock University. His research interests are plagiarism and education, and software to help students. 